\title{
The complexity of bioethics
}

\author{
Richard C. Strohman
}

Like it or not, the biological sciences of today are embedded as never before in a world of fractured social, economic, and political concerns. In this world, it becomes increasingly difficult to discuss all the relationships between the deployment of science-based technology and the many relationships and impacts that deployment might have outside of science/technology, which is usually defined (as it must be) in the confined terms of laboratory experiments. The narrow focus on separated aspects of science in society makes difficult any coherent discussion of ethical principles that might serve to guide us in the use of new and potentially dangerous technologies. However, a way of bridging these separations may be found using the ethical principles found in science itself.

Scientists in the laboratory, corporate researchers and managers who bring the technology/product to the marketplace, individuals who ultimately apply the technology/ product in the real world (farmers or physicians), and end users (consumers, patients, or their representatives) all have responsibilities that are shaped by very different concerns and motives. Public discourse on science is mostly fractured, broken into pieces, where each aspect is discussed separately; the whole picture is made to appear usually as just one part, perhaps more, but never all the parts. Thus, the assumptions of each of the above groups tend to be hidden from all the others. The separation of assumptions is inherently dangerous, especially the scientific assumptions. Scientists' lack of exposure to criticism and rigorous testing in the larger world of application, whether in cornfields or medical centers, exacerbates their incomprehension of public resistance and debate.

One solution may come from the ethical component built into the structure of science itself-one that is often ignored by governmental and corporate structures as funders of research. This component includes the imperative for individual scientists to seek evidence for disproving their hypotheses (e.g., Popper $^{1}$ ), and to consider all, and not just selective evidence (see Whitehead ${ }^{2}$ ). It includes also the historical record showing the capability of "normal science" to uncover the

Richard C. Strohman is in the Department of Cell and Molecular Biology, 229 Stanley Hall \#3206, Berkeley, CA 94720-3206 (strohman@uclink4.berkeley.edu). flaws (anomalies) and misconceptions of a prevailing scientific paradigm $\left(\right.$ see $\mathrm{Kuhn}^{3}$ ). In Kuhn's view, normal science takes Popper's imperative to another level: the scientific community as a whole. In addition, although the above ethical constraints were written with fundamental or basic science in mind, we must also inquire into the ethical constraint that has historically been applied to define the social responsibility of science: the anticipation and control of nature.

Our problem is that the ethical imperatives and demonstrated long-run capacities of normal science may often be seen to be inconsistent with the social responsibilities of science. For example, the need to anticipate and control nature is often acute, or may appear to be acute, as in the case of the present debate around the cause of shortages of food and starvation in the developing world. GMOs are defended as necessary to prevent food shortages, and corporate biotechnology rushes in to provide the answers. However, the fundamental science that provides deep understanding of genetic engineering remains incomplete: long-term research is needed, but this need is in conflict with ideas of perceived urgency.

In addition, there is a demonstrated failure between subdivisions in biology to communicate findings that, if diligently shared, would have prevented the rapid biological evolution of antibiotic-resistant bacteria, drug-resistant viruses, and herbicide- and/or pesticideresistant organisms ${ }^{4}$. Such a failure within the scientific community is an example of a breach of ethics: scientists, regulatory agencies, and the journals working and reporting on GMOs (until quite recently) have often thought (and behaved) in nonscientifically and nonhumanly relevant ways. Quite simply, they are transgressing the code under which they are supposed to be operating.

Thus, given the present reality of science in society, we find a good deal of tension between the social responsibilities of science and the responsibilities of modern corporate technology based on need to produce marketable results in a cost- and time-effective manner.

I give another, broader example demonstrating the complexity inherent in any attempt to bridge the separated elements defining scientific effort. Government (public) and private support of "basic" research is all too often heavy-handed in insisting that all efforts be "sold" under the heading of being able to solve key societal problems, to find a specific mechanism for a complex function, or to address other issues reflected... "in the fluctuating extremes of fashionable opinion"2. Science is mostly a long-range affair, whereas applied technology, relatively speaking, is not. In biomedicine or bioagriculture, the belief is that the organism is a machine directed by genetic parts. When defective or sub standard-indeed, when not perfect-genetic parts can be replaced with perfected parts manufactured in factory-like laboratory settings. In that mechanistic belief, too many disciplines within modern biology fail to ask broader questions having to do the responses made by the organism as a whole to any particular bit of genetic engineering.

We are then left, once again, with the question: "In today's biology dominated by the ethos of mechanism, who will pay for the longterm need to know?" A researcher interested in questioning the role of wholes over parts stands a very poor chance of obtaining support for that kind of question (see refs 5 and 6 for discussion of the impact of metaphor and myth on scientific world-view).

Finally, it is also clear that fundamental discoveries often depend on the freedom of scientists to explore new views of the material world independently of the immediate perceived needs of society. Supporting science to deliver such needs-usually reflecting political, economic, and social concerns - may thus lead to a deterioration of fundamental science and thus to defective applied technologies.

In modern biology, we are now in the midst of a science crisis driven, in part, by the intersection of multiple forces and by a near absence in the body politic of understanding the nature of science, its history, and its relation to philosophy (epistemology). One way to move this fractious debate forward would be to pay independent researchers to do the necessary long-term research, to question the current hypotheses, to deepen our understanding of fundamentals of GMOs and their behaviors over time, and under the varying conditions of nature. But we must also try to broaden the basis of the debate itself, as outlined above.

1. Popper, K. The logic of scientific discovery. (Routledge, Hutchinson, New York,1959).

2. Whitehead, A.N. Science and the modern world. (Cambridge University Press, Cambridge; 1925).

3. Kuhn, T. The structure of scientific revolutions. (University of Chicago Press, Chicago; 1996)

4. Palumbi, S.R. Science 293, 1786-1790 (2001).

5. Lewontin, R. The triple helix. (Harvard University Press, Cambridge, MA; 2000)

6. Rajan, T.V. The Scientist 15, 6 (2001). 